\title{
O Potencial da Produção Associada ao Turismo e o Turismo de Base Comunitária em Joinville-SC
}

\section{Resumo}

Marinês da Conceição Walkowski

O potencial turístico de uma região carece de estudos detalhados dos diversos e complexos componentes da oferta existente. $\mathrm{O}$ conhecimento das informações sobre a riqueza do território do espaço rural do município de Joinville é ainda pouco desenvolvido, não sendo possível, obter dados detalhado do potencial turístico, especialmente da produção associada ao turismo. Neste sentido reside o desafio para o planejamento deste setor em utilizar a geoinformação como ferramenta de gestão do turismo no espaço rural para possibilitar o fortalecimento e a diversificação da oferta turística de Joinville. 0 objetivo desta pesquisa foi demonstrar o potencial da produção associada ao turismo em Joinville, gerando diagramas e cenários de integração para o turismo de base comunitária. Os métodos utilizados foram o geoprocessamento de dados, pesquisa exploratória e descritiva. Por meio do geoprocessamento e fotointerpretação de imagens aéreas de alta resolução foi elaborada a estruturação e integração dos dados, análise do banco de dados e caracterização das unidades familiares e análise do potencial turístico da amostra da pesquisa. Nos resultados, foram obtidos diagramas e cenários de cooperação, caracterizados pelas figuras 1, 2 e 3, além de um portfólio (mapa 2) onde são demonstrados potenciais de cooperação com base nos elementos que interferem na infraestrutura, atrativos naturais e culturais que existem e que poderão compor o produto turístico do espaço rural de Joinville. Concluiu-se que o potencial gerado por meio da integração dos dados, podem auxiliar na geração de cenários de integração e diversificação da oferta turística no espaço rural de Joinville.

Palavras-chave: Turismo; Joinville; Produção associada ao turismo; Turismo de base comunitária.

\section{Abstract \\ The Potential of Production Associated with Tourism and Community Based Tourism in Joinville-SC}

The tourist potential of a region needs detailed studies of the various and complex components of the existing supply. Knowledge of information about the richness of the territory of the city of Joinville is still undeveloped, and it is not possible to obtain detailed data on tourism potential, especially tourism-related production. In this sense lies the challenge for the planning of this sector in using geoinformation as a tourism management tool in the rural area to enable the strengthening and diversification of the tourist offer of Joinville. The objective of this research was to demonstrate the potential of production associated with tourism in Joinville, generating diagrams and integration scenarios for community based tourism. The methods used were data geoprocessing, exploratory and descriptive research. Through the geoprocessing and photointerpretation of high resolution aerial images, the structuring and integration of the data was elaborated, database analysis and characterization of the family units and analysis of the tourist potential of the research

a. Pós-doutora em Turismo e Hotelaria pela Universidade do Vale do Itajaí (UNIVALI). Docente do curso de Gestão de Turismo no Instituto Federal de Santa Catarina (IFSC), Florianópolis, Santa Catarina, Brasil. E-mail: marinesw@gmail.com 
sample. In the results, cooperation diagrams and scenarios were obtained, characterized by figures 1, 2 and 3, plus a portfolio (map 2) where cooperation potentials are demonstrated based on the elements that interfere in the infrastructure, natural and cultural attractions that exist and that can compose the tourist product of the rural area of Joinville. It was concluded that the potential generated through the integration of the data, can help in the generation of scenarios of integration and diversification of the tourist offer in the rural area of Joinville.

Keywords: Tourism; Joinville; Production associated with tourism; Community-based tourism.

\section{Resumen}

\section{El potencial de la producción asociada al turismo y el turismo comunitario en Joinville-sC}

El potencial turístico de una región necesita estudios detallados de los diversosy complejos componentes de la oferta existente. El conocimiento de la información sobre la riqueza del territorio de la ciudad de Joinville aún no se ha desarrollado, y no es posible obtener datos detallados sobre el potencial del turismo, especialmente la producción relacionada con el turismo. En este sentido, el desafío para la planificación de este sector es el uso de la geoinformación como herramienta de gestión del turismo en el área rural para permitir el fortalecimiento y la diversificación de la oferta turística de Joinville. El objetivo de esta investigación fue demostrar el potencial de producción asociado con el turismo en Joinville, generando diagramas y escenarios de integración para el turismo basado en la comunidad. Los métodos utilizados fueron datos de geoprocesamiento, investigación exploratoria y descriptiva. A través del geoprocesamiento y fotointerpretación de imágenes aéreas de alta resolución, se elaboró la estructuración e integración de los datos, el análisis de la base de datos y la caracterización de las unidades familiares y el análisis del potencial turístico de la muestra de investigación. En los resultados, hemos obtenido diagramas y escenarios de cooperación, caracterizados por las figuras 1, 2 y 3, más un portfolio (mapa 2) donde se demuestra un potencial de cooperación basado en los elementos que interfieren en la infraestructura, los atractivos naturales y culturales que existen y que pueden componer el producto turístico del área rural de Joinville. Se concluyó que el potencial generado a través de la integración de los datos, puede ayudar en la generación de escenarios de integración y diversificación de la oferta turística en el área rural de Joinville.

Palabras clave: turismo; Joinville; Producción asociada al turismo; Turismo de base comunitaria.

\section{INTRODUÇÃo}

O estudo da identificação da produção associada ao turismo, caracterizada pelo artesanato, produção agropecuária e pelo patrimônio natural e cultural poderá contribuir para a expansão de outras atividades econômicas internas, resultando em novos segmentos de mercado para o turismo no espaço rural.

A produção associada ao turismo vinculada ao turismo de base comunitária pode ser considerada uma estratégia de inclusão social, à medida que permite que pequenas empresas e/ou iniciativas formais e informais façam parte de uma cadeia turística. Possibilita diversas parcerias entre os serviços (hospedagem, agência, alimentação, entre outros), por meio da cooperação e dinamização do produto turístico, promovendo uma maior interação entre os atores locais. 
Os hotéis e restaurantes, por exemplo, podem ofertar produtos coloniais nas refeições e as agências de viagens podem obter roteiros diversificados no espaço rural (agroturismo, turismo de natureza, atividades de lazer e venda de produtos coloniais, entre outros) (Tomazzoni, 2007; Manzanares, Mateos, 2017).

0 planejamento dos recursos territoriais, que constituem a matéria prima do turismo, deve abranger a acessibilidade, a estrutura básica de alojamentos, restaurantes e demais estabelecimentos, assim como os atrativos (naturais e culturais) que propiciam o deslocamento de turistas e os comportamentos humanos. O planejamento do território visa o desenvolvimento local ou regional, em função das políticas que vem sendo adotadas e que visam à melhoria na qualidade de vida da população (Manzanares, Mateos, 2017; Moraleda, Mazón, Izquierdo, 2016; Moreno, Villareal, 2017).

Segundo Pecqueur (1992), o espaço-território exerce forte influência no desenvolvimento, deixando de ser apenas um suporte aparente e torna-se um elemento de organização produtiva que vai influir nas estratégias dos atores individuais e das empresas.

Para Lefebvre (2000), o espaço passa a ser influenciado pelo modo de produção realizada por cada sociedade e torna-se diacrônico e dotado de uma simultaneidade dinâmica, permitindo assimilar espaço-tempo, múltiplo pela sua própria condição de ser proveniente destas realidades e possibilidades.

A lógica territorial é de construir e fortalecer interdependências entre os setores econômicos e entre as esferas políticas, sociais e espaciais. Para tanto, a constituição de redes de instituições apresenta uma correlação direta com a estrutura e a qualidade dos serviços existentes, além da apropriação por meio de representações sociais (Cazella, 2006).

Para Raffestin (1993) o território é produto dos agentes sociais, do Estado ao indivíduo, passando por todas as organizações, pequenas ou grandes e está relacionado as atribuições dos atores sociais que ocupam, atuam e tem ação política sobre o espaço. Portanto, "o espaço é, de certa forma, "dado" como se fosse uma matéria-prima". Já o território "se apoia no espaço, mas não é o espaço. É uma produção, a partir do espaço" (Raffestin, 1993, p. 144).

A estruturação dos dados possibilita uma visão estratégica do setor produtivo associado ao turismo. Mais do que simplesmente tratar dados e gerar controle, irá subsidiar a tomada de decisão, visando fornecer ao gestor em turismo informações estratégicas como as possibilidades de cooperação (cenários) e projetos integrados para dinamizar a oferta turística e definir políticas a serem adotadas. Ainda, pode ser levado em consideração os elementos objetivos e subjetivos existentes nas unidades homogêneas de paisagem e que irão compor o planejamento integrado (Manzanares, Mateos, 2017).

0 turismo tem gerado renda em grande parte dos municípios do Estado de Santa Catarina. Faz-se necessário pensar em alternativas inovadoras que poderão ser incorporadas às Políticas Nacionais, Estaduais, Regionais e Municipais como forma de articular os atores locais e amenizar as dificuldades encontradas pelas famílias que residem no campo. No entanto, foram encontrados poucos estudos que abordam métodos sobre o levantamento da produção associada ao turismo e os parâmetros e critérios para a análise da sua potencialidade em relação aos destinos turísticos e a integração e cooperação das iniciativas locais. Nesse contexto, surge o questionamento sobre quais as possibilidades de cooperação/ 
integração e inclusão social das famílias envolvidas na produção associada ao turismo e no turismo de base comunitária?

0 presente artigo é resultado de uma tese de doutorado e fruto de uma pesquisa bibliográfica durante o estágio de pós-doutorado da autora da pesquisa. Tem por objetivo, demonstrar o potencial da produção associada ao turismo em Joinville, gerando diagramas e cenários de integração para o turismo de base comunitária. Na metodologia de análise, foi utilizada a pesquisa exploratória e descritiva. Os dados foram coletados no Município de Joinville, a partir de pesquisa documental, pesquisa bibliográfica em livros e periódicos nacionais e internacionais, observações em campo, entrevista semiestruturada e questionário estruturado e observações indiretas. Os dados foram estruturados por meio de um Sistema de Informações Geográficas (SIG) e construídos diagramas e cenários demonstrando o potencial de articulação da produção associada ao turismo e do turismo de base comunitária no território de Joinville-SC.

\section{REVISÃo DE LITERATURA}

\section{Produção Associada ao Turismo: uma proposta de integração}

Os sistemas produtivos localizados têm sido objeto de discussão em diferentes políticas nacionais como alternativa de dinamização territorial.

No final dos anos 1970, os casos das experiências italianas dos distritos industriais constituídos por redes de pequenas e médias empresas (PME), conhecido como a "Terceira Itália", apresentaram uma dinâmica de desenvolvimento particular por meio do modelo de industrialização difusa deixando clara a importância do planejamento territorial (Carrière, Cazella, 2006). A noção de Distritos Industriais se consagrou em função das relações entre as dinâmicas industriais e dinâmicas territoriais e sua origem se deu a partir das obras de Alfred Marshall, que fundamentaram as realizações industriais e das formas espaciais dos processos de industrialização difusa surgidas nas regiões do centro e do nordeste da Itália nas décadas de 1960 e 1970. A teoria consiste em articular os recursos econômicos, sociais e culturais existentes num dado território, gerando crescimento das economias externas e maior eficiência ao sistema empresarial (Courlet, 2006).

A diferença das indústrias localizadas em relação às demais ocorre com os benefícios alcançados na produção de maquinário, insumos consumidos, gerando eficiência coletiva por meio do trabalho especializado, redução dos custos de transporte e proximidade do mercado consumidor, gerando externalidades positivas. A eficiência coletiva ou vantagem competitiva se dá em função das ações conjuntas manifestadas por firmas individuais cooperando e grupos de firmas reunindo forças em associações empresariais, consórcios de produtos, entre outros (Garcia, Costa, 2005; Desjardins, Boucher, Cerdan, 2006).

A partir da década de 90 e com base na evolução conceitual dos Sistemas Produtivos Localizados que o termo Arranjo Produtivo Local passou a ser utilizado com maior frequência como sendo um espaço social, econômico e historicamente construído, a partir de uma aglomeração de empresas (ou produtores) similarese/ou fortemente inter-relacionadas ou interdependentes que interagem numa escala espacial local definida e limitada através de fluxos de bens e serviços (Costa, 2010). 
Este conceito passou a evoluir desde que os chamados "novos espaços produtivos" foram postos em debate com o surgimento da chamada era da flexibilidade formada por uma nova visão de integração e interação dos processos multidimensionais e interdependentes, compondo um Sistema Industrial Pós-Moderno ou Regime de Acumulação Flexível (Costa, 2010).

Em função dos efeitos gerados por essa discussão, surgiu a Rede de Pesquisa em Sistemas Produtivos e Inovativos Locais (REDESIST), sediada no Instituto de Economia da Universidade Federal do Rio de Janeiro, desde 1997. A noção de cadeia produtiva é criada inicialmente por meio de um processo de desverticalização da produção e pela especialização técnica e social. A contribuição dessa rede pode ser observada com a elaboração de um glossário onde são apresentados os principais conceitos e definições acerca da temática.

Segundo o Glossário de Arranjos e Sistemas Produtivos e Inovativos Locais (2003), a aglomeração de empresas e o aproveitamento das sinergias geradas por suas interações fortalecem suas chances de sobrevivência e crescimento, constituindo-se em importante fonte de vantagens competitivas duradouras. A participação dinâmica em arranjos produtivos locais tem auxiliado empresas, especialmente as de micro, pequeno e médio portes a aumentarem a eficiência em mercados nacionais e internacionais. Já, os arranjos produtivos locais são aglomerados territoriais de agentes econômicos, políticos e sociais com foco em um conjunto específico de atividades econômicas que apresentam vínculos mesmo que incipientes.

Para Cassiolato et al. (2008), no Brasil as políticas voltadas para o APL ocorreram com a criação de um Grupo de trabalho permanente para arranjos produtivos locais (GTPAPL) no âmbito do Ministério do Desenvolvimento (MDIC) e a ação da política regional no âmbito do Ministério da Integração Nacional, visando ampliar a competitividade e sustentabilidade econômica dos APL. Contudo, o APL tem ocorrido em um contexto em que é observado o abandono por parte da política tornando-se incipientes em termos de número, características de atores e dinâmica; inadequação de vários mecanismos de política implementadas; necessidade de aperfeiçoamento e burocracias legais de financiamentos. Essa realidade tem sido comum na maioria dos destinos, gerando diversos conflitos e segregação populacional.

Sendo assim, o levantamento proposto e a estruturação das informações são fundamentais para que ocorra o entendimento dos potencias turísticos existentes no território em questão.

\section{Produção associada ao turismo e a dinamização dos espaços rurais}

A Produção Associada ao Turismo tem sido vista por muitos destinos como uma alternativa de dinamização à medida que são incorporados novos produtos e serviços, auxiliando na geração de emprego e renda para a população local.

Segundo o Manual para o Desenvolvimento e a Integração de Atividades Turísticas (Brasil, Mtur, 2011), o estudo da produção incentiva a criação de um ambiente interativo e colaborativo entre os produtores locais e os empresários do setor, estabelecendo parcerias e uma relação de troca entre os envolvidos. 0 referido manual ressalta a importância em identificar e mapear os possíveis canais 
de comercialização de atividades turísticas para o desenvolvimento integrado da região. Para tanto, são necessárias informações de qualidade que identifiquem as vocações e as potencialidades locais para o planejamento de uma atividade responsável, integrada, coordenada e participativa. É um processo gerador de integração dos empreendimentos e fortalecimento do destino local e regional.

Observa-se que tal processo se torna uma estratégia territorial de longo prazo que envolve tanto os produtores, os agentes da transformação e as cooperativas, quanto às instituições de coordenação do desenvolvimento local a partir de uma oferta construída de bens e serviços específicos e distintos. Geralmente os produtos levam em consideração uma identidade e o contexto do local e resultam em estratégias de promoção da qualidade da produção agrícola, possibilitando o surgimento de redes, troca de informação, cooperação e aprendizagem (Pecqueur, 2006; Bursztyn, Bartholo, 2013).

No Brasil as iniciativas voltadas à produção associada ao turismo estão presentes em diferentes regiões e ocorrem de forma bem pontual e incipiente e não dispõem de informações consistentes ou os mesmos são genéricos e incompletos. Os casos mais comuns encontrados estão presentes nos seguintes Estados: RS, AL, MG, SP, RJ, PR, GO, MT, PB, RN, AM, BA e SC. Contudo, nem todos se encontram estruturados e em condições de comercialização ao turista.

\section{Turismo de base comunitária e a valorização da cultura local}

$\mathrm{Na}$ atualidade, observa-se que o desenvolvimento da atividade turística tem se originado a partir de iniciativas endógenas locais e/ou regionais baseadas em iniciativas comunitárias. Tal fato se comprova pelas diretrizes do atual Programa Nacional de Regionalização do Turismo, cujo enfoque está voltado para promover a cooperação entre os atores locais e as instituições de gestão pública e/ou privada, a fim de promover um turismo de forma mais sustentável.

0 turismo comunitário é aquele em que as comunidades de forma associativa organizam arranjos produtivos locais, possuindo o controle efetivo das terras e das atividades econômicas associadas à exploração do turismo. Trata-se de um desenvolvimento local ou endógeno, compreendido como o processo de crescimento económico e de mudança estrutural, liderado pela comunidade e com a sua participação ativa, realizado na perspectiva da satisfação das suas próprias necessidades (Coriolano, 2009; Mayaka, Croy \& Cox, 2017; Holladay \& Powell, 2013).

Para Bursztyn, et al. (2009), o Turismo de Base Comunitária (TBC) é aquele onde as sociedades locais possuem controle efetivo sobre o seu desenvolvimento e gestão. Ocorre por meio de envolvimento participativo em todo o processo, desde o início, onde as ações voltadas ao turismo deverão propiciar a maior parte dos benefícios para a população local, além de promover a troca de experiências no local visitado.

Para Pine II e Gilmore (1999), uma experiência não é um constructo nulo, é uma oferta como qualquer serviço, bem ou mercadoria. Neste sentido, se faz importante perceber os benefícios de encenar experiências e promover momentos memoráveis com base nas especificidades locais.

A noção de turismo de base comunitária no Brasil surgiu por meio de Encontros de Turismo de Base Local (ENTBL) em 1997, configurando-se como um dos 
principais eventos acadêmicos na reflexão sobre o fenômeno turístico e seus impactos. A partir de então, diversas iniciativas ocorreram entre os anos de 1998 e 1999, se consolidando em 2003 com a realização do primeiro Seminário de Turismo de Base comunitária, reunindo diversas iniciativas de TBC no Brasil (Irving, 2009).

O conceito de Turismo de Base Comunitária - TBC nasce considerando a perspectiva de se pensar em um melhor aproveitamento dos aspectos produtivos que podem integrar uma região e auxiliar no planejamento para se obter uma maior eficiência econômica, social e ambiental. No final do século XX e início de século XXI, observa-se que o desenvolvimento de algumas atividades turísticas vem ocorrendo a partir de iniciativas endógenas locais e/ou regionais, baseadas em iniciativas comunitárias. Tal fato se comprova pelas diretrizes do atual Programa Nacional de Regionalização do Turismo, cujo enfoque está voltado para promover a cooperação entre os atores locais e as instituições de gestão pública e/ou privada, a fim de promover um turismo de forma mais sustentável (Bursztyn, et al, 2009).

As associações cumprem o papel de ser um novo ente turístico, um agente intermediário entre as articulações do Estado em políticas para o turismo e a vontade competitiva do empreendedor privado. Elas servem de instrumento de mobilização das comunidades em que estão inseridos os atrativos e empreendimentos, necessárias para a organização de eventos, marketing e atividades que envolvam muita gente e dinamizam os roteiros, criando uma mentalidade solidária e coletiva, de colaboração e ajuda mútua, diluindo os fracassos e fazendo com que as conquistas sejam de todos (Brambatti, Nitsche, 2018).

Um exemplo emblemático da criação do TBC ocorreu com a Rede de Turismo Comunitário da América Latina (REDTURS) que foi criada em 2001, com o objetivo de articular redes que vêm sendo construídas em diferentes escalas local e nacional, com a finalidade de diversificar as possibilidades de emprego e renda, de valorizar a cultura local e de fomentar o associativismo (Moraes, et al, 2017).

O maior potencial do TBC está na participação da comunidade no fazer a atividade turística, como parte integral do desenvolvimento sustentável do turismo, onde a comunidade expressa seus desejos e suas aspirações sociais e o TBC abre esse espaço para que a localidade, mesmo com sua individualidade, se envolva em uma construção coletiva em busca de melhor qualidade de vida (Gómez, et al, 2015; Moraes, et al, 2017; Sampaio, Zamignan, 2012).

O chamado turismo comunitário surge como contraposição ao chamado turismo convencional ou de massa. Para Bursztyn et al (2009), Pires (2009), Ruschmann (1999) e Mano, et al (2017), um exemplo de turismo de massa são os grandes empreendimentos (resorts) que acabam provocando a especulação imobiliária e a descaracterização da cultura local. Este fato fez com que algumas comunidades lutassem por seus direitos, resultando na criação de um turismo alternativo ou comunitário. Muitas dessas comunidades se concentravam no espaço rural ou espaços em que comunidades tradicionais como pescadores artesanais, grupos quilombolas, indígenas e outros grupos minoritários como os extrativistas vivem. Porém, é no espaço rural que muitas destas experiências de turismo vêm ocorrendo.

Ainda em relação ao TBC, em pesquisas mais recentes, observa-se dificuldades para o seu desenvolvimento em redes na América Latina. Dentre as dificuldades apontadas por Moraes (2017), está a limitada capacidade de gestão das redes de turismo comunitário; a falta de qualidade da oferta de prestação de serviços com 
relação à demanda; a elevada dependência de recursos externos; a limitação de membros envolvidos no processo; o estabelecimento de relações informais; a inexistência de políticas públicas específicas para esse tipo de iniciativa; e a forte influência do setor turístico convencional, baseado na lógica do mercado nesse contexto.

Apesar das dificuldades apontadas acima, o Estado de Santa Catarina, devido sua vocação para a atividade turística, tem investido em novas atividades no espaço rural que vem crescendo cada vez mais por meio de iniciativas de diferentes organizações não-governamentais e entidades voltadas ao setor turístico. Tal fato tem despertado o interesse dos municípios em diminuir as desigualdades sociais e buscar novas alternativas de dinamização das atividades agrícolas e não agrícolas. Muitas dessas atividades surgiram ante a necessidade de dinamizar as atividades no campo na tentativa de resgatar a autoestima do agricultor e revitalizar o espaço rural. As novas atividades não agrícolas também chamadas de agricultura pluriativa, são uma forma de incrementar a renda familiar. Dentre os segmentos do turismo no espaço rural, o agroturismo pode ser considerado uma alternativa de turismo sustentável, contribuindo com o desenvolvimento territorial à medida que oferece aos visitantes, o convívio com o ambiente natural por meio de alimentos saudáveis, lazer e preservação da natureza e da cultura local (Guzzatti, 2010).

A prática de TBC exige uma nova forma de olhar para os problemas sociais, culturais e ambientais das comunidades de destino. Essa nova concepção de turismo é também influenciada pelas mudanças no perfil do turista contemporâneo, o qual busca por experiências turísticas com valores naturais e culturais que primam pela autenticidade e originalidade dos lugares e pela responsabilidade e preocupação com a biodiversidade, por meio da interação com a comunidade visitada (Moraes, et al, 2017; Silva, Cristoffoli, 2016).

\section{METODOLOGIA}

Em função da diversidade existente, os métodos podem ser classificados em dois grandes grupos: os que proporcionam as bases lógicas da investigação científica e os que esclarecem os procedimentos técnicos que podem ser utilizados (Gil, 2011). Esta pesquisa será focada em métodos que proporcionem os meios técnicos para garantir a objetividade e a precisão no estudo dos fatos sociais.

A presente pesquisa adotou uma abordagem interdisciplinar, baseada em duas vertentes: a pesquisa qualitativa e quantitativa.

Na metodologia de análise foi utilizada a pesquisa exploratória e descritiva. Os dados foram coletados no Município de Joinville a partir de pesquisa documental, pesquisa bibliográfica em livros e periódicos nacionais e internacionais, entrevista semiestruturada e questionário estruturado e observações indiretas em campo. A partir da identificação e caracterização da produção associada à paisagem local e dos atores que interferem na atividade turística no espaço rural foi alimentado o SIG utilizando como ferramenta o ArcGIS 10.2. A entrevista semiestruturada e questionário estruturado foram aplicados com as propriedades com potencial turístico pertencentes as Bacias Hidrográficas do rio Cubatão do Norte e rio Piraí, durante os anos de 2013 a 2014.

$\mathrm{Na}$ pesquisa bibliográfica identificam-se referências que embasam a temática utilizada. Dentre os principais autores estão: Coriolano (2009), 
Cassiolatto, Bartholo (2003), Cazella (2006); Garcia, Costa (2005), Sampaio (2012), Brasil, MTur (2011), Pecqueur (2006) e Ruschmann (1999), Bursztyn, et al, (2009), Pires (2009), entre outros.

Dentre as ferramentas que foram utilizadas para analisar o potencial turístico com base na produção associada ao turismo, estão: o Sensoriamento Remoto, o uso de produtos fotogramétricos e fotointerpretação, o Geoprocessamento e o Sistema de Informações Geográficas, que possibilitam gerar diversos produtos cartográficos temáticos para o turismo, visualizar as inter-relações existentes no espaço rural e a integração entre os mesmos, além de auxiliar na tomada de decisão no planejamento turístico e na gestão territorial.

Para se coletar dados relativo à caracterização das unidades familiares, foi elaborado um questionário em conjunto com a equipe de pesquisa interdisciplinar do laboratório de Fotogrametria, Sensoriamento Remoto e Geoprocessamento da UFSC, que atua neste projeto. 0 questionário teve como meta localizar e coletar as informações no município para alimentar um SIG e está estruturado com as seguintes questões: a relação do número da amostra, à caracterização da propriedade familiar, a localização, aos meios de acesso, aos usos do solo, às condições jurídicas, à infraestrutura, às condições de saneamento como, por exemplo, abastecimento de água, destino do lixo, entre outros. Também foram coletadas informações sobre o padrão demográfico, a descrição das cadeias e produtos principais, bem como as práticas produtivas locais. A disponibilidade de apoio financeiro às unidades familiares, instituições de apoio que atuam na área, à percepção de meio ambiente. Identificou-se o potencial para atividade turística, a infraestrutura mínima para receber visitantes, adequação das instalações, os equipamentos próximos da propriedade (os meios de hospedagem existentes, principais estabelecimentos integrantes da rede de estabelecimentos gastronômicos, agências de viagens, operadoras, equipamentos de lazer e entretenimentos - casas de shows, estádios, parques, exposições, entre outros), onde foram observadas as belezas cênicas. Foi levantado se a propriedade possui potencial para atividade turística com algum atrativo natural ou cultural que pudesse despertar ainda mais o interesse de visitantes como: cachoeiras, edificações antigas, artesanato local, culinária típica, entre outros.

Também foi elaborado um roteiro de entrevista não estruturada que permite maior flexibilidade à medida que, por meio de questões abertas, podem ser incorporadas novas informações e questionamentos sempre que necessário. As questões elaboradas foram referentes à existência de planos e projetos em andamento e futuros; se recebem recursos do governo federal ou estadual; a existência de ações em conformidade com as políticas de turismo estaduais e federais; a participação do órgão responsável pelo turismo na Instância de Governança; quais áreas e setores necessitam de investimento para um melhor desenvolvimento da entidade; a relação da entidade com as demais instituições de gestão territorial; a relação das entidades com os empreendimentos da área de turismo e comunidade, levando em consideração a frequência em reuniões, ações conjuntas, relação com o conselho municipal de turismo; a existência de um sistema de avaliação de indicadores turísticos do município e como são coletadas as informações.

Os materiais utilizados foram obtidos no Sistema de Informações Municipais Georreferrenciadas (SIMGeo) de Joinville e referem-se à Restituição Aerofotogramétrica de 2010 e arquivos digitais do tipo Shapefile dos pontos 
turísticos das Bacias Hidrográficas do rio Cubatão do Norte e rio Piraí. Os arquivos do tipo shapefile dos limites das Bacias Hidrográficas foram extraídos do Sistema de Informação da EPAGRI (SIGEO).

Também foram utilizados documentos oficiais das secretarias da administração pública e das instituições de gestão territorial que foram trabalhados ao longo da pesquisa.

\section{RESULTADOS E DISCUSSões}

Os resultados da pesquisa foram obtidos com a aplicação em diferentes etapas, as quais buscaram, de forma sistêmica, alcançar os objetivos propostos.

Foram aplicados 22 questionários com agricultores, dentro e fora das unidades familiares nas localidades do Rio Piraí, Rio Quiriri, Rio da Prata e Dona Francisca. A saída a campo foi realizada nos dias 14, 15 e 16 de dezembro de 2011 e o questionário foi aplicado pela equipe do Laboratório de Fotogrametria, Sensoriamento Remoto e Geoprocessamento.

As entrevistas foram realizadas nos dias 22 e 23 de novembro de 2012, com os principais representantes e membros das seguintes entidades: Fundação Eco Rural, Fundação de Promoção e Planejamento Turístico de Joinville (PROMOTUR), Associação dos Proprietários de Terras da Mata Atlântica com Recursos Hídricos (APROAGUA), Associação Joinvillense de Agroindústrias Artesanais Rurais (AJAAR) e Fundação Municipal de Desenvolvimento Rural 25 de Julho. Os dados também foram complementados a partir de informações secundárias nos inventários turísticos existentes, relatórios oficiais, sites oficiais e demais publicações especializadas do município - cedidos pelos membros das referidas instituições de gestão territorial. Nesta ocasião também foram realizadas visitas em algumas agroindústrias e empreendimentos familiares, a fim de conhecer a realidade e obter imagens fotográficas das mesmas.

Inicialmente foi criada uma tabela contendo as coordenadas geográficas de pontos de interesse da pesquisa, obtidos por receptor de GPS e alimentados no ARCGIS.

0 banco de dados foi alimentado ainda, com relatórios disponibilizados pelas instituições de gestão territorial e a Fundação Turística e Secretaria Municipal de Planejamento (SEPLAN), por meio de dados em formato shapefile (shp) que trouxe informações como: a estrutura fundiária, curvas de nível, divisa de bairros, divisa de distrito, hidrografia, vegetação, vias, rodovias e estrutura fundiária.

A escolha das duas bacias hidrográficas como área de estudo (Mapa 1), se deu em função da representatividade do espaço rural em relação ao município. Em Joinville, o espaço rural possui uma área de $898 \mathrm{~km} 2$, representando 81\% no município, que possui uma área de $1.134,03 \mathrm{~km} 2$. A bacia hidrográfica do rio Piraí possui uma área de $311,37 \mathrm{~km} 2$, representando $27 \%$ do município e a bacia hidrográfica do rio Cubatão Norte possui uma área de 490,72 km2 e representa 43\%. 0 espaço urbano possui uma área de $237 \mathrm{~km} 2$ e representa $19 \%$. Contudo, a população no espaço rural representa apenas $3 \%$ do total no município, enquanto que a população no meio urbano representa $97 \%$. Esse fato demonstra que o espaço rural ainda vem sendo pouco ocupado e necessita de melhores oportunidades de geração de emprego e renda para a população e melhor aproveitamento do potencial turístico existente. 
Mapa 1 - Produção associada ao turismo e localização da área de pesquisa.

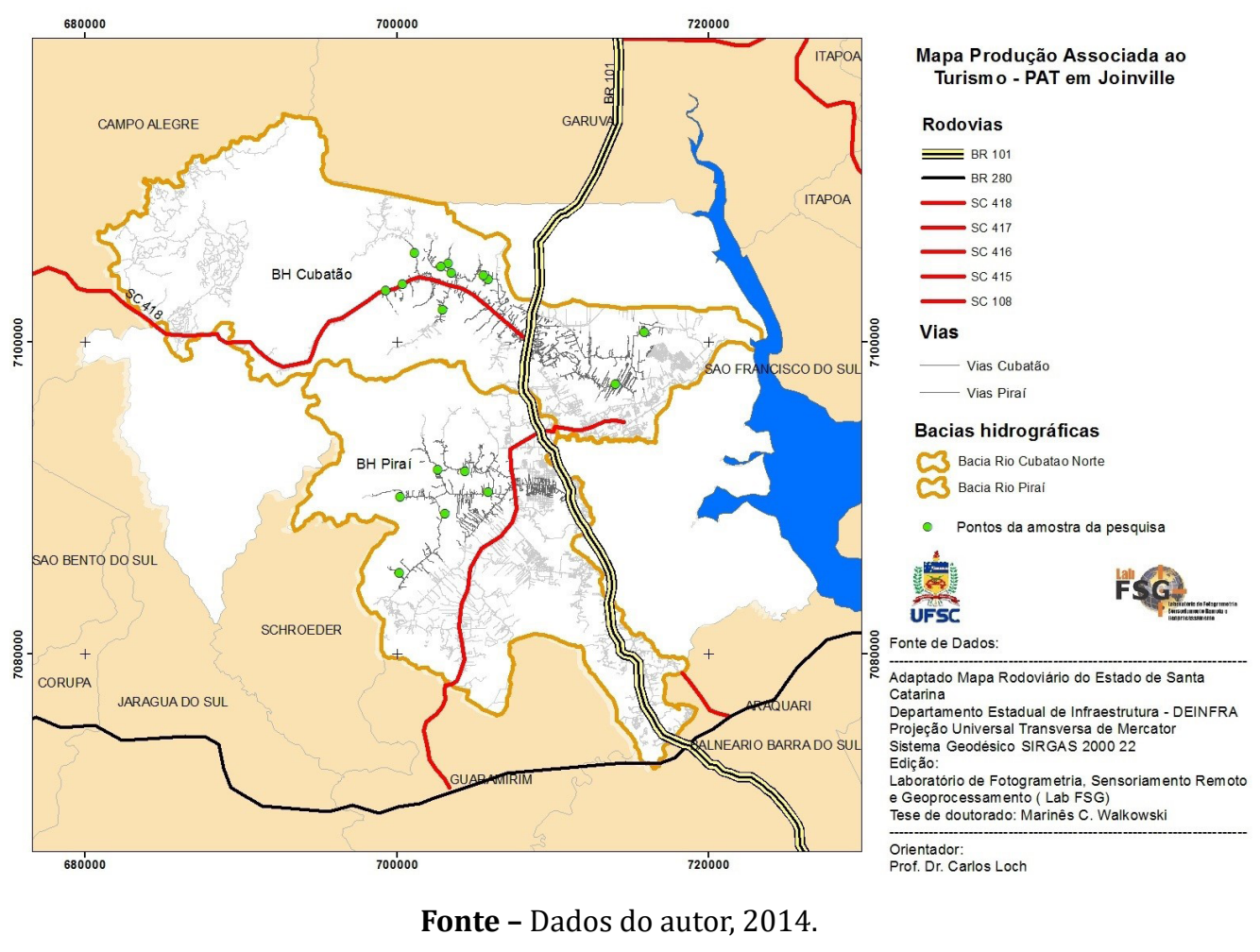

A partir do banco de dados elaborado em ArcGIS foi possível realizar as análises quanto às características das propriedades da amostra da pesquisa. Foram selecionadas da amostra da pesquisa 5 propriedades (unidades familiares) com potencial turístico, sendo três da Bacia hidrográfica do Piraí e 2 da Bacia hidrográfica do Cubatão do Norte, de acordo com as características extraídas do banco de dados do ArcGIS.

Em relação a caracterização das 5 unidades familiares pesquisadas: ambas são unidades familiares próprias e de pessoa física e todas necessitam de adaptação para receber turistas. A principal fonte de renda é a agricultura, sendo 2 propriedades de produção convencional e 3 de produção orgânica. Vale ressaltar que as unidades familiares participam de projeto de turismo pedagógico chamado Viva Ciranda, coordenado pela Fundação de Promoção e Planejamento Turístico de Joinville (Promotur) e com o apoio da Secretaria de Educação. 0 Viva Ciranda incentiva escolas da rede pública e da rede privada a trabalharem educação ambiental e outros assuntos escolares através da visitação às pequenas propriedades rurais e caracteriza-se como um projeto de turismo de base comunitária.

Após o detalhamento das 5 unidades familiares, cruzando com os dados do banco de dados e da estruturação das informações foi possível desenhar cenários de cooperação entre estas unidades familiares, entendendo de que forma poderão cooperar e integrar a produção associada ao turismo, fortalecendo a prática da atividade turística. 
No primeiro cenário, no diagrama abaixo (Figura 1) são observadas as 5 unidades interagindo entre si, na forma de uma teia, onde cada uma está relacionada com as outras 4 unidades restantes:

Figura 1 - Diagrama - Cenário.

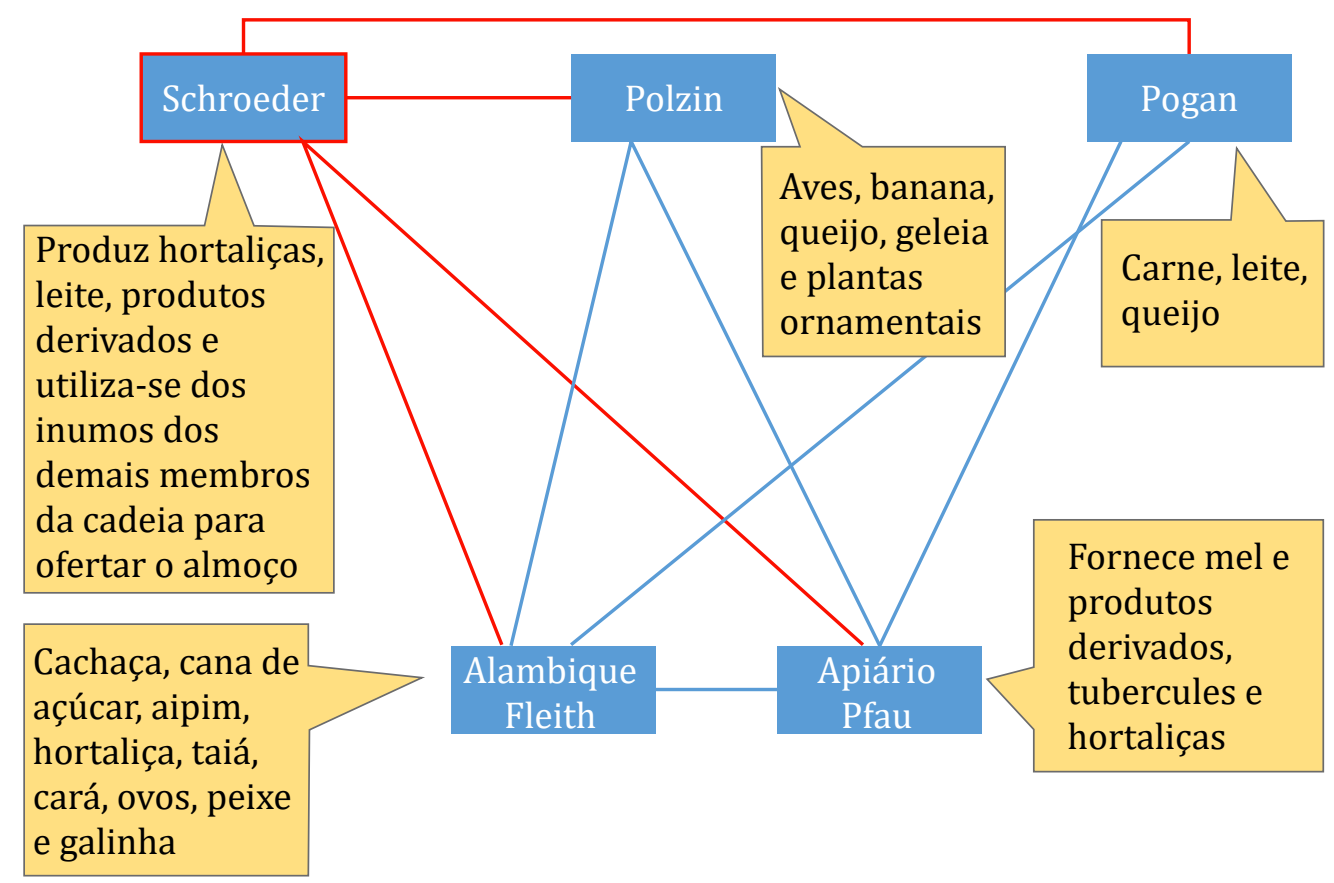

Fonte - Dados do autor, 2014.

Neste cenário (Figura 1), parte-se do pressuposto de que a unidade familiar Schroeder está recebendo um determinado Grupo A de visitantes em excursão pelo município e que agendou um almoço em sua propriedade. A família Schroeder não possui todos os insumos necessários para esta demanda e de uma forma associada, utiliza-se do relacionamento com as demais propriedades para obter os insumos necessários para servir o almoço. As demais propriedades criam uma relação de fornecimento de mercadorias para a família Schroeder.

Outra possibilidade de cenário seria a unidade familiar Polzin que, além de acomodar este grupo de visitantes, oferece produtos cultivados nas demais propriedades associadas, criando um comércio de produtos locais. 0 principal insumo já é produzido no local e as demais unidades participam fornecendo seus produtos coloniais, gerando a diversificação necessária para atender os visitantes.

Em outro cenário, a unidade familiar Alambique Fleith possui um museu da produção de cachaça que passa a atrair uma gama de visitantes. A cachaça já é o atrativo principal, porém este fluxo de visitantes é uma excelente oportunidade para aumentar a receita da propriedade. Neste sentido, uma área para o comércio dos produtos e espaço para refeições poderá manter os visitantes por mais tempo na propriedade e aumentar o consumo e a oferta de produtos aos demais associados. 
Criada a relação entre estas unidades familiares e aproveitando dos demais atrativos do entorno das propriedades, percebe-se a gama potencial de atrativos capaz de manter os turistas na região, conforme diagrama abaixo (Figura 2):

Figura 2 - Diagrama - Cenário.

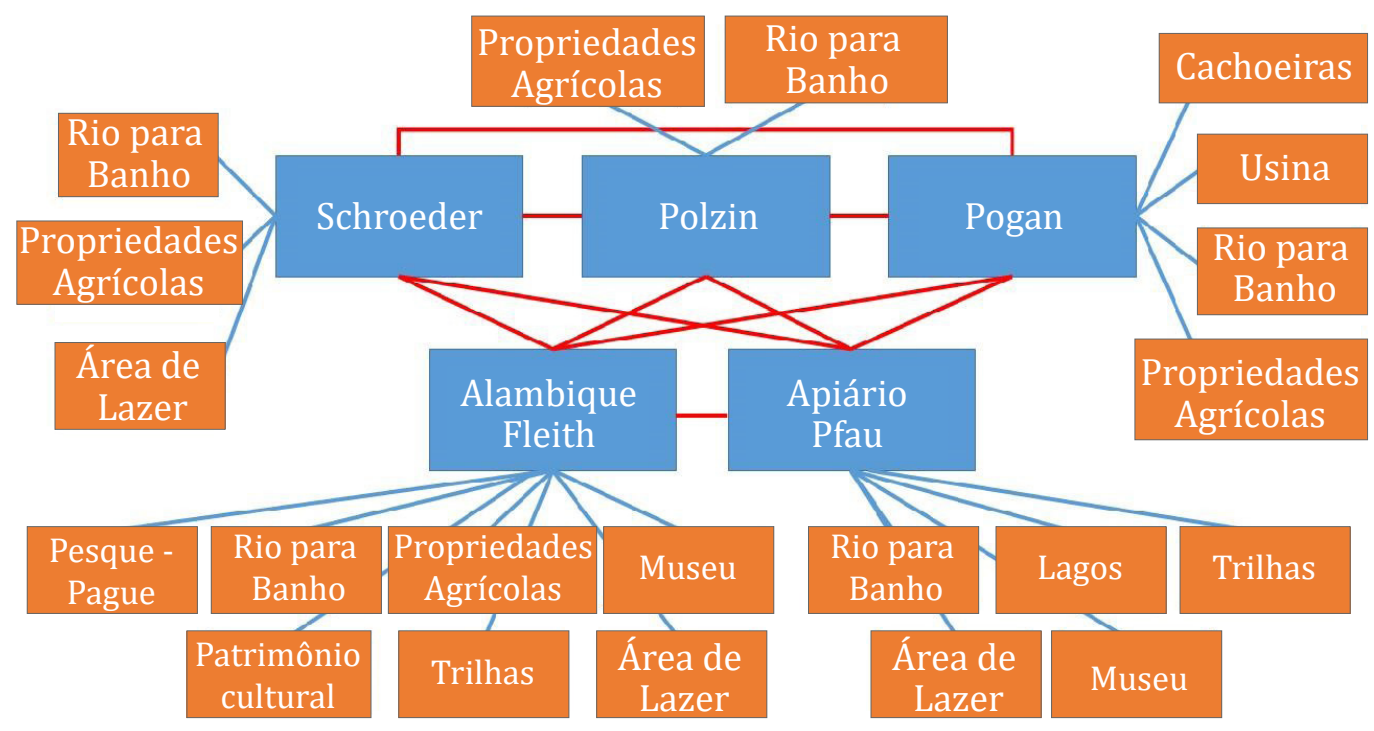

Fonte - Dados do autor, 2014.

Percebe-se que, além dos atrativos das unidades já demonstrados anteriormente, o entorno destas propriedades possui uma gama de possibilidades para retenção dos visitantes, o que ajuda a toda a cadeia turística envolvida. Uma vez sensibilizada a região e preparados os atrativos de forma a receberem os visitantes com a infraestrutura necessária, é possível elaborar roteiros envolvendo o todo ou parte desta cadeia produtiva do turismo.

0 diagrama abaixo (Figura 3) mostra um exemplo de roteiro elaborado para atender um grupo de visitantes.

Figura 3 - Diagrama - Cenário e proposta de roteiro.

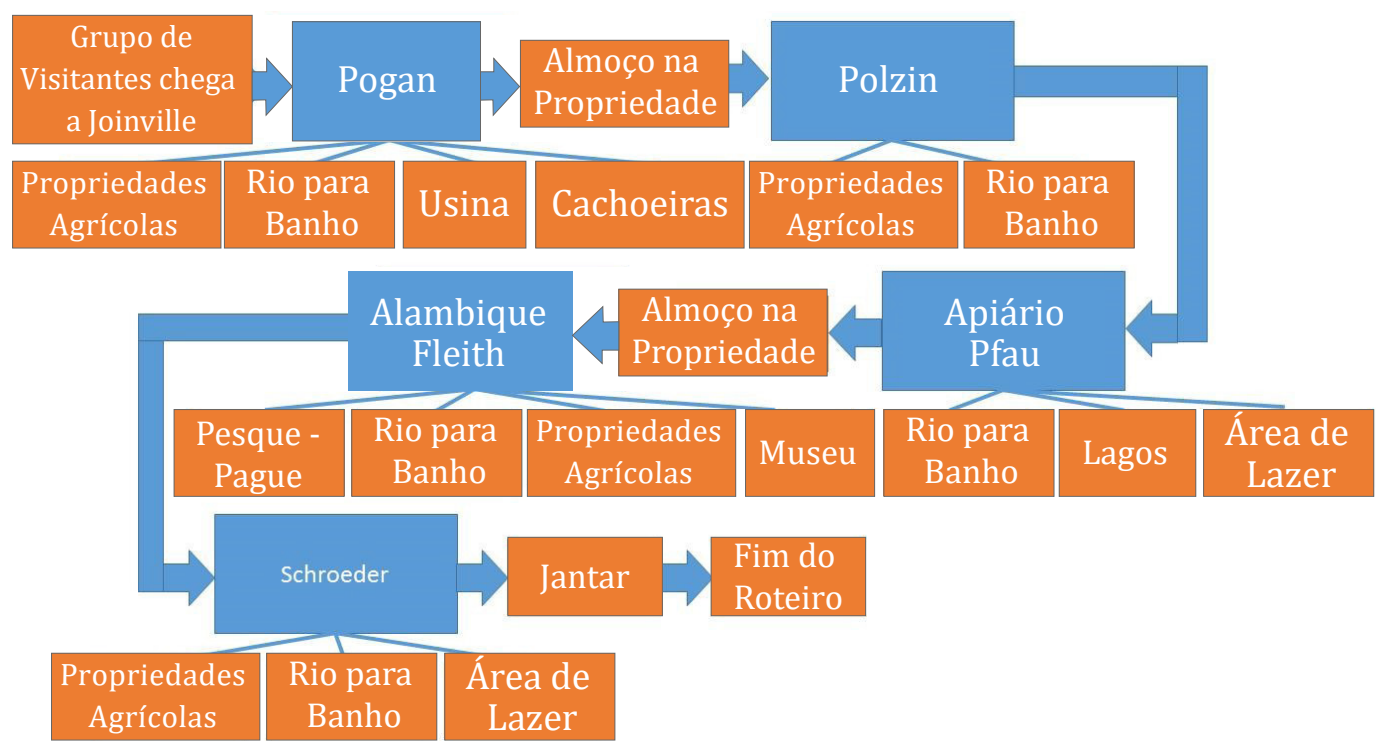

Fonte - Dados do autor, 2014. 
No roteiro proposto pelo diagrama acima, o grupo de visitantes é recebido na unidade familiar Pogan que possui a criação de aves exóticas. Além disso, o entorno oferece atrativos capazes de reter estes visitantes. Em outro período, o grupo de visitantes se desloca para a unidade familiar Polzin para conhecer o processo de cultivo mecanizado e comprar produtos locais dos associados. No Apiário Pfau, são ofertados um café da tarde com a produção de mel e insumos das demais unidades. Em seguida, o grupo se desloca para o Alambique Fleith, onde conhecem o processo de fabricação e degustação de cachaça e venda de produtos locais. Por fim, o grupo se desloca para a unidade da família Schroeder, que possui estrutura para oferecer um jantar dançante aos visitantes.

Os cenários representados pelos Diagramas (1, 2 e 3) demonstram o potencial de articulação que irá auxiliar no desenvolvimento de iniciativas de Turismo de base comunitária a partir do empoderamento das unidades familiares e interesse em cooperação e preservação do patrimônio natural e cultural ainda existente.

Além dos cenários demonstrados foi proposto criação de um Portfólio da Produção Associada ao Turismo, conforme Mapa 2:

Mapa 2 - Portfólio da produção associada ao turismo.

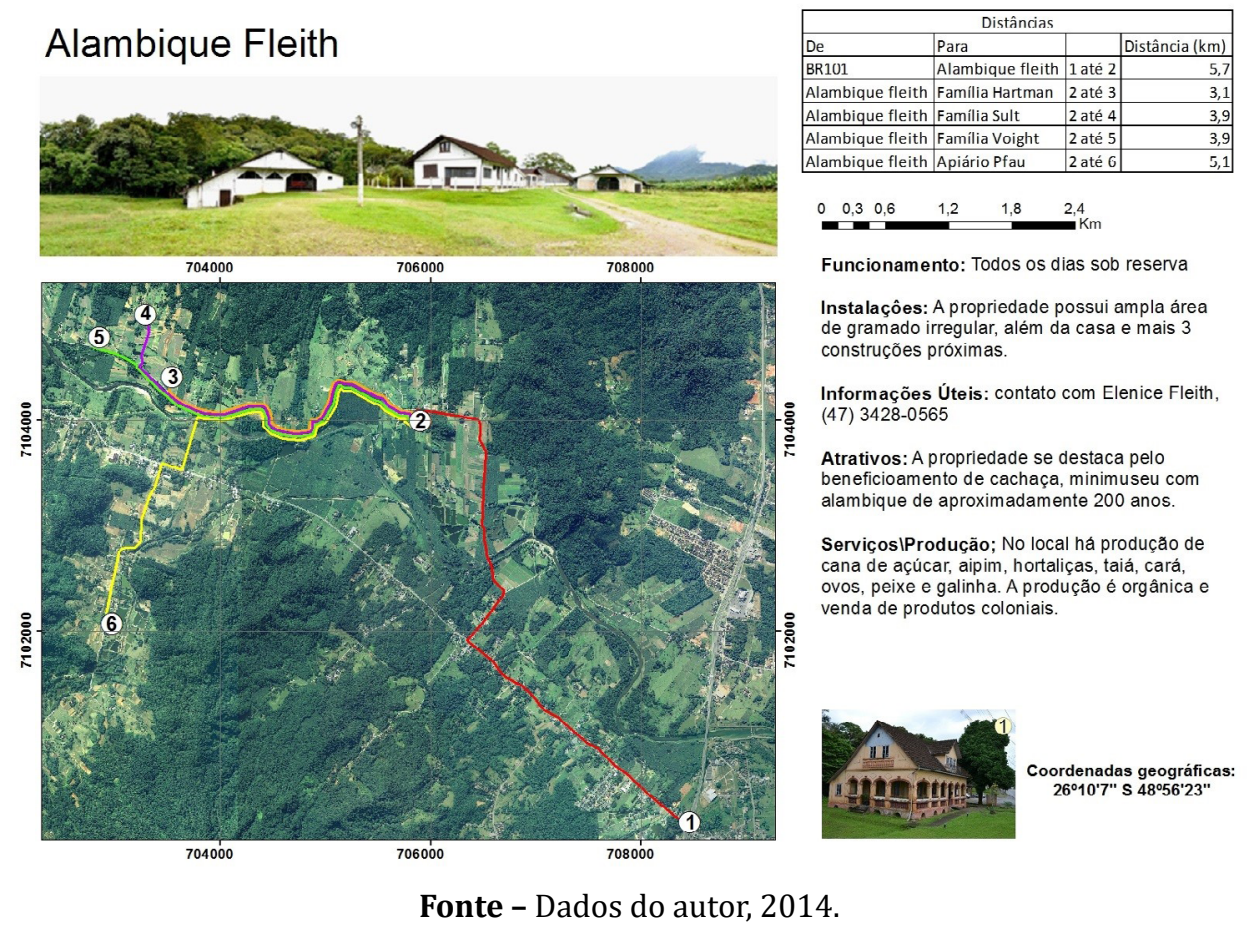

O objetivo do portfólio é possibilitar que uma pessoa, sem conhecimento prévio do local, possa se locomover e decidir sobre eventuais visitas a outras propriedades, além de mostrar a proximidade e as possibilidades de interação, cooperação e trocas entre as propriedades (unidades familiares) envolvidas.

0 portfólio (mapa 2) demonstra o quanto é possível manipular os dados obtidos e gerar produtos a fim de planejar, desenvolver, criar material de divulgação, localização, de controle e de estudo da região para conhecimento do potencial da produção associada ao turismo. No mapa, representado por uma das amostras da pesquisa (Alambique Fleith), é demonstrado as distâncias e localização entre as unidades familiares e os atrativos e serviços ofertados. 


\section{CONCLUSÃo}

O município de Joinville apresenta um potencial turístico ainda pouco desenvolvido em função da falta de sensibilização e de articulação no território. Neste sentido, a presente pesquisa visou apontar alternativas de dinamização dos produtos e serviços, a fim de aumentar a atratividade e competitividade do destino tendo como alternativa a cooperação e integração entre as unidades familiares.

0 objetivo geral proposto na pesquisa foi alcançado por meio da estruturação dos dados, demonstrando as possibilidades de integração de informações, visando à valorização da produção associada ao turismo, além de possibilitar o conhecimento do potencial turístico no território, a fim de auxiliar no planejamento integrado e no fortalecimento do turismo de base comunitária.

Com base nas visitas a campo, entrevistas e análise dos documentos, ressalta-se que as Bacias Hidrográficas desse município possuem vias bem sinalizadas e os acessos às propriedades são considerados em bom estado. A estrutura fundiária demonstrou que o espaço rural é predominantemente de agricultores familiares, influenciando a paisagem local. A produção local é bem limitada em função das dificuldades de comercialização e atração de visitantes. Em função da proximidade com o meio urbano, observou-se um aumento da multifuncionalidade e pluriatividade no campo, limitando a criação de novas atividades de turismo e oportunidade de emprego e renda para os jovens em suas propriedades. Essas características auxiliaram na estruturação e integração dos dados, fundamental para gerar informação de qualidade.

0 potencial no espaço rural de Joinville, especialmente nas bacias hidrográficas do rio Cubatão do Norte e Piraí, pode ser evidenciando pela produção agropecuária, artesanal e do patrimônio natural e cultural, bem como o potencial de compra e venda direta entre os produtores das comunidades locais (oferta), demonstrados a partir dos diagramas e cenários de articulação e cooperação.

Conclui-se que o método utilizado nessa pesquisa possibilitou uma visão estratégica e integrada do potencial de cooperação e articulação existente no território de Joinville, evidenciado pelos diagramas compostos por cenários e portfólios, a partir da estruturação dos dados, utilização das metodologias qualitativas e quantitativas e alimentação de um SIG. Nesse sentido, o método utilizado poderá auxiliar o profissional de turismo, a partir do uso de ferramentas como a fotointerpretação e o geoprocessamento, na elaboração de diagnósticos mais eficazes e na proposição de planos e projetos condizentes com a realidade local, apresentando o potencial existente, ainda pouco explorado pelas instituições de gestão territorial. Além disso, a metodologia proposta possibilita ser adaptada a diferentes realidades, abrindo ainda mais o campo de trabalho para os profissionais de turismo.

Em relação a inserção social ocorre ainda com a atuação dos atores locais por meio de iniciativas de turismo de base comunitária a partir do empoderamento das unidades familiares e interesse em cooperação e preservação do patrimônio natural e cultural, também demonstrado no portfólio (mapa 2).

0 Turismo de Base Comunitária é uma alternativa viável para as comunidades locais, atraindo um público cada vez mais voltado para a consciência ambiental e a valorização da cultura local, além de possibilitar a oferta e o fortalecimento da produção associada ao turismo como mais uma opção de renda e diversificação da oferta turística em Joinville. 


\section{REFERÊNCIAS}

Brambatti, L. E \& Nitsche, L. B. (2018). Associativismo e Participação Comunitária: o Roteiro Rural Caminhos de Guajuvira, Araucária-PR, Brasil. Revista Rosa dos Ventos Turismo e Hospitalidade 1(10): 71-84

Brasil, Ministério do Turismo. (2011). Diretrizes para o Desenvolvimento do Turismo Rural no Brasil. Brasília.

Bursztyn, I. et al. (2009). Turismo para quem? Sobre caminhos de desenvolvimento e alternativas para o turismo no Brasil. In: Bartholo, R.; Sansolo, D.G. \& Bursztyn, I. (2009). Turismo de Base Comunitária diversidade de olhares e experiências brasileiras. Rio de Janeiro: Editora Letra e imagem, parte I: 76 - 91

Bursztyn, I. \& Bartholo, R. (2013). La valoración del diálogo en la construcción e implementación de rutas turísticas: Proyectos Palacios de Rio y Central de Turismo Comunitario de la Amazonia Brasil. Estudios y Perspectivas en Turismo 22: 1160 - 1181

Cassiolato, J. E, Lastres, H. M. M \& Maciel, M. L. (2008). 0 foco em Arranjo s Produtivos e inovativos locais de micro e pequenas empresas. In: Cassiolato, J. E, Lastres, H. M. M \& Maciel, M. L. (Orgs.) Pequena Empresa: cooperação e desenvolvimento local. Rio de Janeiro: Relume Dumará

Cazella, A \& Carrière, J. P. (2006). Abordagem introdutória ao conceito de desenvolvimento territorial. In: Eisforia, Universidade Federal de Santa Catarina (2003), Centro de Ciências Agrárias, Programa de Pós-Graduação em Agrecossistemas 1(1), Florianópolis: PPGAGR

Coriolano, L. N. M. T. (2009). Arranjos produtivos locais do turismo comunitário: atores e cenários em mudança. Fortaleza: EdUECE

Costa, E. J. M. (2010). Arranjos produtivos locais, políticas públicas e desenvolvimento regional. Brasília: Mais Gráfica, 402

Courlet, C. (2006). Os sistemas produtivos localizados: da definição ao modelo. In: Eisforia/ Universidade Federal de Santa Catarina, Centro de Ciências Agrárias, Programa de PósGraduação em Agrecossistemas. v. 1, n. 1 (2003), Florianópolis: PPGAGR

Desjardins, D., Boucher, F. \& Cerdan, C. (2006). Globalization, Competitive Advantages and the Evolution of Production Systems: Rural Food Processing and Localized Agri-food Systems in Latin American Countries. Entrepreneurship and Regional Development 15(1): 49-67

Garcia, J. R. \& Costa, A. J. D. (2005). Sistemas produtivos locais: uma revisão da literatura. Recuperado em 08 de dezembro de 2011, de https://www.fae.edu/publicacoes/pdf/ IIseminario/.../iniciacao_09.pdf

Gil, A. C. (2011). Métodos e técnicas de pesquisa social. Sexta edição. São Paulo: Atlas

Gómez, C. R. P. et al. (2015). Turismo de Base Comunitária como Inovação Social: congruência entre os constructos. Pasos. Revista de Turismo y Patrimonio Cultural 13(5):1213-1227

Guzzatti, T. (2010). $O$ agroturismo como elemento dinamizador na construção de territórios rurais: O caso da Associação de Agroturismo Acolhida na Colônia em Santa Rosa de Lima (SC). Florianópolis. Tese doutorado em geografia, Universidade Federal de Santa Catarina

Glossário de Arranjos e Sistemas Produtivos e Inovativos Locais. (2003). Recuperado em 08 de dezembro de 2011, de http://www.redeaplmineral.org.br/biblioteca/glossario-dearranjos-e-sistemas-produtivos-e-inovativos-locais

Holladay, P. J. \& Powell, R. B. (2013). Resident perceptions of social-ecological resilience and the sustainability of community-based tourism development in the Commonwealth of Dominica. Journal of Sustainable Tourism, 16(3), 1188-1211

Irving, M. A. (2009). Reinventando a reflexão sobre turismo de base comunitária: inovar é possível? In: Bartholo, R.; Sansolo, D. G. \& Bursztyn, I. Turismo de Base Comunitária 
diversidade de olhares e experiências brasileiras. Rio de Janeiro: Editora Letra e Imagem, parte I:108-121

Lefebvre, H. (2000) La production de l'espace. 4. ed. Paris: Éditions Anthropos.

Manzanares, A. F. A, Mateos, H. M. S. (2017). El acesso a los destinos rurales: uma perspectiva para la planificación territorial del turismo em uma región de interior (Castilla-la Mancha). Cuadernos de Turismo, n. 40, p. 251-272

Mayaka, M; Croy, W. G. \& Cox, J. W. (2017). Participation as motif in community-based tourism: a practice perspective. Journal of Sustainable Tourism, 16(8), 416-432

Moraes, E. A.; Irving, M. A.; Santos, J. S. C.; Santos, H. Q. \& Pinto, M. C. (2017). Redes de turismo de base comunitária: reflexões no contexto latino-americano. Revista Brasileira de Ecoturismo, São Paulo, 9(6): 612-623

Moraleda, L. F., Mazón, A. M., Izquierdo, S. R. (2016). El turismo solidário como instrumento de desarrollo: um estúdio de caso para analizar las principales motivaciones de los turistas. Cuadernos de Turismo, 37, 227-242.

Moreno, I. A. C. \& Villarreal, L. Z. (2017). Alcances de la política social y el turismo rural para el desarrollo local em San Mateo Almomoloa - México. Estudios y Perspectivas en Turismo 26: $944-963$

Pine, B. J., \& Gilmore, J. H. (1999). The experience economy: work is theatre \& every business a stage. Harvard Business Press

Pires, P. dos S. et al. (2009). Estruturação de matriz de impactos do turismo: o caso do agroturismo no município de Santa Rosa de Lima - SC. Revista Brasileira de Pesquisa em Turismo 3(1): 68- 89

Pecqueur, B. (1992). Territoire, territorialite et developpement. In: Coloque Industrie et Territoire, IREPD, Grenoble: 20-22

Pecqueur, B. (2006). A guinada territorial da economia global. In: Eisforia/Universidade Federal de Santa Catarina, Centro de Ciências Agrárias, Programa de Pós-Graduação em Agroecossistemas. v. 1, n. 1 (jan./jun., 2003) Florianópolis: PPGAGR

Raffestin, C. (1993). Por uma geografia do Poder. São Paulo: Ática

Ruschmann, D. V. M. (1999). Turismo e planejamento sustentável: a proteção do meio ambiente. 5. ed. Campinas, SP: Papirus

Sampaio, C. A. C. \& Zamignan, G. (2012). Estudo da demanda turística: experiência de turismo comunitário da Microbacia do rio sagrado, Morretes (PR). CULTUR, ano 06(1): 25-39

Silva, Y, \& Cristoffolli, A. R. (2016). Turismo rural comunitário: Gestión familiar y estrategias de consolidación en el Estado de Santa Catarina (Brasil). Estudios y Perspectivas en Turismo 25: $576-596$

Tomazzoni, E. L. (2007). Turismo e desenvolvimento regional Modelo APLTur aplicado à região das Hortênsias (Rio Grande do Sul - Brasil). Doutorado em Ciências da Comunicação na área de concentração Relações Públicas, Propaganda e Turismo, na Linha de Pesquisa Turismo e Lazer. São Paulo

\section{CONTRIBUições}

Marinês da Conceição Walkowski: Autoria única. 